\title{
Application Decision Support System using PROMETHEE Method
}

\author{
*Ade Parlaungan Nasution, Dapartment of Management, STIE Labuhan Batu, Indonesia \\ Dahrul Aman Harahap, Department of Education Management, STKIP Labuhan Batu, Indonesia \\ Ronal Watrianthos, Department of Informatics Management, AMIK Labuhan Batu, Indonesia
}

\begin{abstract}
Decision making is a condition that must occur at various top management levels and sometimes interventions or conflict of interest occur in making decisions. Preference Ranking for Organization Method for Enrichment Evaluation (PROMETHEE) is a method that can be used to help decision makers in this case the best student selection decision at a university. Tests carried out using the PROMETHEE method can produce a complete ranking by eliminating the low value of each process in the PROMETHEE method and by develop application using programming language it's much faster to get decision.
\end{abstract}

Keywords--- Application DSS, Decision Support System, Promethee

\section{Introduction}

Determination of student pretensions is a matter that needs to be determined quickly and precisely. In terms of determining outstanding students, a number of considerations are needed that are quite numerous and complicated, namely standardization of values, requirements and policies of the university that change frequently every year. To obtain high-achieving and quality students in academics, the process of selecting students must determine the appropriate criteria and must be prepared to the maximum extent possible.

Because the selection process is still manual, so it is considered to be less than optimal and requires a considerable amount of time both in compiling the report and deciding the outstanding student must be determined as soon as possible to support the other system. To solve the above problems it is necessary to make a decision support system application to assist the university in selecting outstanding students.

Decision Support System[1]-[4] is used as an alternative application system that helps in making decisions for the determination of outstanding students. Decision making generally uses data and models to solve unstructured problems to be structured[5], so that the process of implementing student achievement can be done better. In making decisions there are several difficulties faced, including the various values that are processed, there are factors or criteria that influence the choices available[6], [7]. The process of determining student prescriptions is done for several classes that meet certain criteria including the problem of Multiple Criteria Decision Making (MCDM)[8]-[10] so that the settlement requires a Decision Support System. Another uniqueness of the Decision Support System is that there is a facility that is able to integrate the system installed with the user interactively, known as the dialog subsystem.

The method used in decision making is PROMETHEE (Preference Ranking for Organization Method For Enrichment Evaluation) method[11], [12]. This PROMETHEE method is a form of decision support model for decision making with various criteria and can be used to solve decision-making problems that rely on it as the main input. Decision support systems using the PROMETHEE method are able to analyze the criteria and alternatives that are compared and can provide alternative students with achievements that match the values and abilities of students.

\section{Methodology}

Decision making in an organization is the result of a continuous process of communication and participation of the entire organization[10]. The issue of decision making is basically a form of selection of various alternative actions that may be selected for which the process is through a certain mechanism, with the hope that it will produce the best decision. Preparation of a decision model is a way to develop logical relationships that underlie the problem of decision into a mathematical model, which reflects the relationship between the factors involved. Decision Support Systems can provide benefits or benefits for the wearer[13]. Such benefits include:

a. Extending the ability of decision makers in processing data / information for users.

b. Helping decision makers in terms of saving the time needed to solve problems, especially various problems that are very complex and unstructured.

c. Provide solutions faster and the results are reliable.

*Corresponding Author: Ade Parlaungan Nasution,Email id : Shenbab4u@gmail.com 
d. Although a Decision Support System, it may not be able to solve problems faced by decision makers, but it can be a stimulant for decision makers in understanding the problem. Because the decision support system is able to present various alternatives.

e. Decision Support Systems can provide additional evidence to provide justification so that it can strengthen decision-making positions.

Besides the various advantages and benefits as stated above, the Decision Support System also has a number of limitations, including:

a. There are several management abilities and human talents that cannot be modeled, so that the models in the system do not reflect the real problem.

b. The ability of a DSS is limited to the treasury of knowledge it has (basic knowledge and basic models).

c. The processes that can be performed by DSS usually depend also on the capabilities of the software it uses.

d. The decision support system does not have the intuition ability as possessed by humans. Because despite how sophisticated a DSS is, it is just a collection of hardware, software and operating systems that are not equipped with the ability to think.

PROMETHEE (Preference Ranking Organization Method for Enrichment Evaluation) is one of the methodologies in multi-criteria decision making[11], [14]. This methodology can be used to find the best alternative based on an assessment of several specified criteria. PROMETHEE is one of the rankings in the Multiple Criteria Decision Making. The definition of the PROMETHEE method is a method of determining the order (priority) in multi-criteria analysis. The main problem is simplicity, clarity, and stability. The presumption of the dominance of the criteria used in PROMETHEE is the use of values in outranking relationships. PROMETHEE functions to process data, both quantitative and qualitative data at once. Where all data is combined into one with the weight of the assessment that has been obtained through assessment or survey. The calculation steps with the PROMETHEE method are as.

a. Determination of alternative values from data.

b. Determine the type of preference function and preference value.

c. Calculation of preference index.

d. Calculation of preference direction is considered based on index values leaving flow, enter-flow and net flow.

$$
\varphi(a 1, a 2)=\sum_{i=1}^{k} \pi \mathrm{P}_{i}(a 1, a 2) ; \forall a 1 a 2 \varepsilon A
$$

\section{Result and Discussion}

The assessment process in determining students who have achieved so far is done manually. Assessment is done by using a percentage for each student without regard to the activities that each of the criteria has.

The value of each student to be accepted will be compared with the scores of other participants. The system does not have a certain standard value and the parameter values and weights for each of the free criteria are determined based on management conditions. The parameter value and the given weight state the priority order of criteria. The system only provides information on the results of the assessment in the form of ranking in ascending order.

Table 1. Sample Value

\begin{tabular}{|l|c|l|l|l|l|l|l|l|l|}
\hline No & Criteria & C1 & C2 & C3 & C4 & C5 & C6 & C7 & Total \\
\hline 1 & A1 & 80 & 90 & 77 & 83 & 28 & 42 & 50 & 450 \\
\hline 2 & A2 & 80 & 75 & 75 & 85 & 32 & 53 & 60 & 460 \\
\hline 3 & A3 & 70 & 80 & 90 & 60 & 40 & 70 & 60 & 470 \\
\hline 4 & A4 & 70 & 89 & 78 & 69 & 30 & 54 & 90 & 480 \\
\hline 5 & A5 & 89 & 70 & 78 & 69 & 30 & 44 & 40 & 404 \\
\hline 6 & A6 & 66 & 70 & 71 & 89 & 29 & 66 & 40 & 431 \\
\hline 7 & A7 & 80 & 66 & 89 & 67 & 33 & 90 & 53 & 478 \\
\hline 8 & A 8 & 90 & 81 & 77 & 65 & 32 & 76 & 88 & 509 \\
\hline 9 & A9 & 87 & 86 & 90 & 66 & 34 & 54 & 78 & 495 \\
\hline 10 & A10 & 78 & 68 & 80 & 76 & 33 & 89 & 55 & 479 \\
\hline 11 & A11 & 89 & 60 & 60 & 70 & 30 & 78 & 45 & 432 \\
\hline 12 & A12 & 75 & 75 & 83 & 70 & 31 & 65 & 76 & 475 \\
\hline 13 & A13 & 65 & 65 & 60 & 60 & 30 & 83 & 81 & 444 \\
\hline 14 & A14 & 70 & 79 & 64 & 67 & 32 & 91 & 59 & 462 \\
\hline
\end{tabular}

*Corresponding Author: Ade Parlaungan Nasution,Email id : Shenbab4u@gmail.com 


\begin{tabular}{|l|l|l|l|l|l|l|l|l|l|}
\hline 15 & A15 & 70 & 89 & 90 & 66 & 35 & 97 & 69 & 516 \\
\hline 16 & A16 & 90 & 90 & 76 & 76 & 35 & 50 & 66 & 483 \\
\hline 17 & A17 & 87 & 78 & 60 & 70 & 31 & 90 & 54 & 470 \\
\hline 18 & A18 & 65 & 66 & 60 & 71 & 33 & 78 & 85 & 458 \\
\hline 19 & A19 & 66 & 76 & 60 & 72 & 32 & 96 & 56 & 458 \\
\hline 20 & A20 & 78 & 89 & 67 & 73 & 30 & 88 & 89 & 514 \\
\hline
\end{tabular}

After the calculation process of the criteria values displayed in the table, the next step is to calculate the multicriteria preference index, while the results of the sample data count are as follows:

$$
\varphi(a 1, a 2)=\sum_{i=1}^{k} \pi \mathrm{P}_{i}(a 1, a 2) ; \forall a 1 a 2 \varepsilon A
$$

The formula above is made in stages and displays the results of PROMETHEE based on the existing values, here is the PROMETHEE result table.

Table 2. PROMETHEE Result

\begin{tabular}{|l|c|c|}
\hline \multicolumn{1}{|c|}{ No } & Alternative & Value \\
\hline 1 & A1 & 0,735 \\
\hline 2 & A2 & 0,685 \\
\hline 3 & A3 & 0,66 \\
\hline 4 & A4 & 0,679 \\
\hline 5 & A5 & 0,679 \\
\hline 6 & A6 & 0,62 \\
\hline 7 & A7 & 0,65 \\
\hline 8 & A8 & 0,70 \\
\hline 9 & A9 & 0,723 \\
\hline 10 & A10 & 0,67 \\
\hline 11 & A11 & 0,618 \\
\hline 12 & A12 & 0,658 \\
\hline 13 & A13 & 0,53 \\
\hline 14 & A14 & 0,644 \\
\hline 15 & A15 & 0,7 \\
\hline 16 & A16 & 0,739 \\
\hline 17 & A17 & 0,655 \\
\hline 18 & A18 & 0,59 \\
\hline 19 & A19 & 0,619 \\
\hline 20 & A20 & 0,675 \\
\hline
\end{tabular}

Table 2 above shows the results of calculations using the PROMETHEE method and the highest value from the table A16 is an alternative alternative compared to other alternatives, for applications that implement the methods Promethee can be seen in Figures 1 to 3 below. 


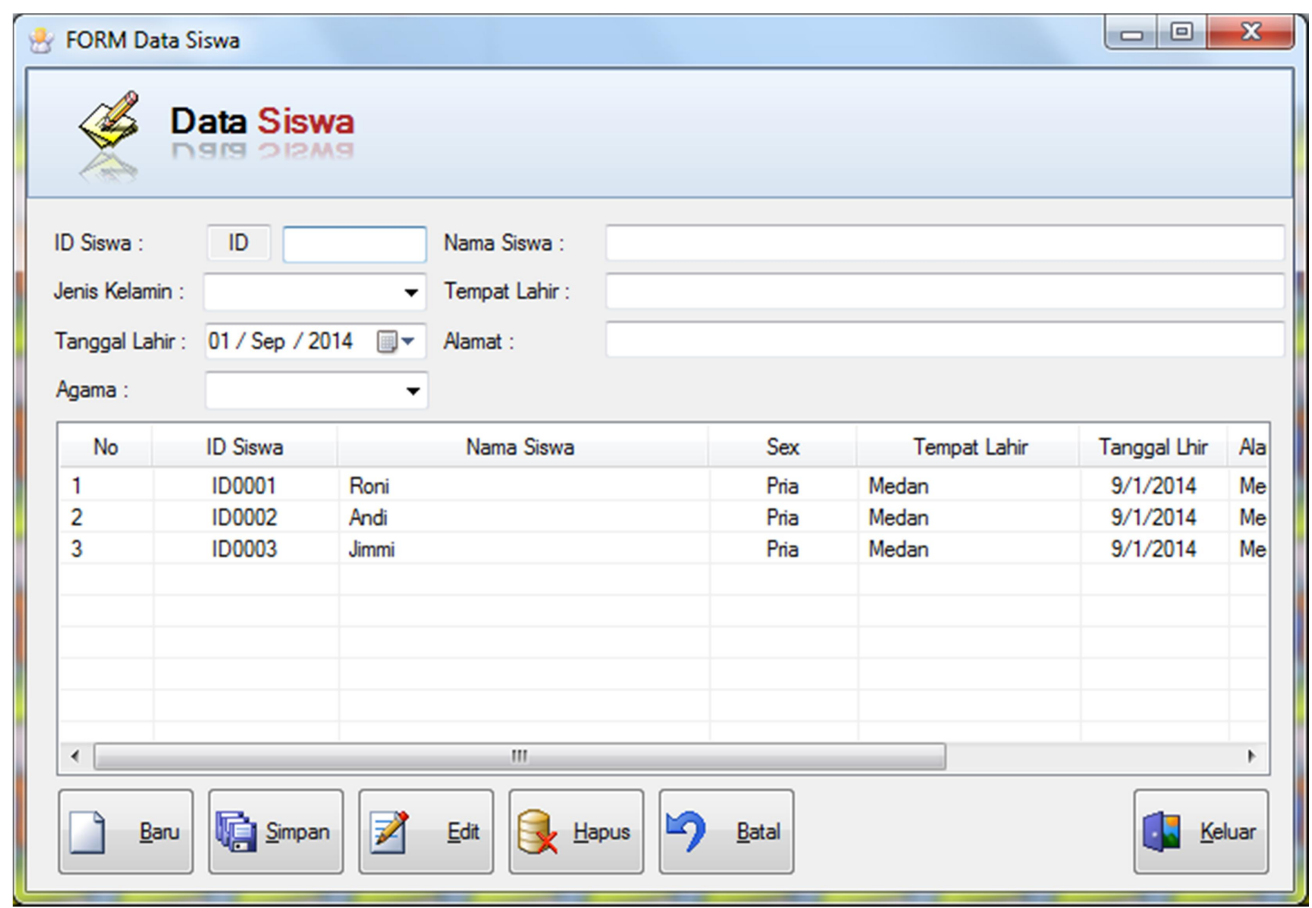

Figure 1. Master Student

Figure 1 is an interface that is used to input student data which will be processed using the PROMETHEE method, and in this data there's will be at least 20 sample data as in table 1.

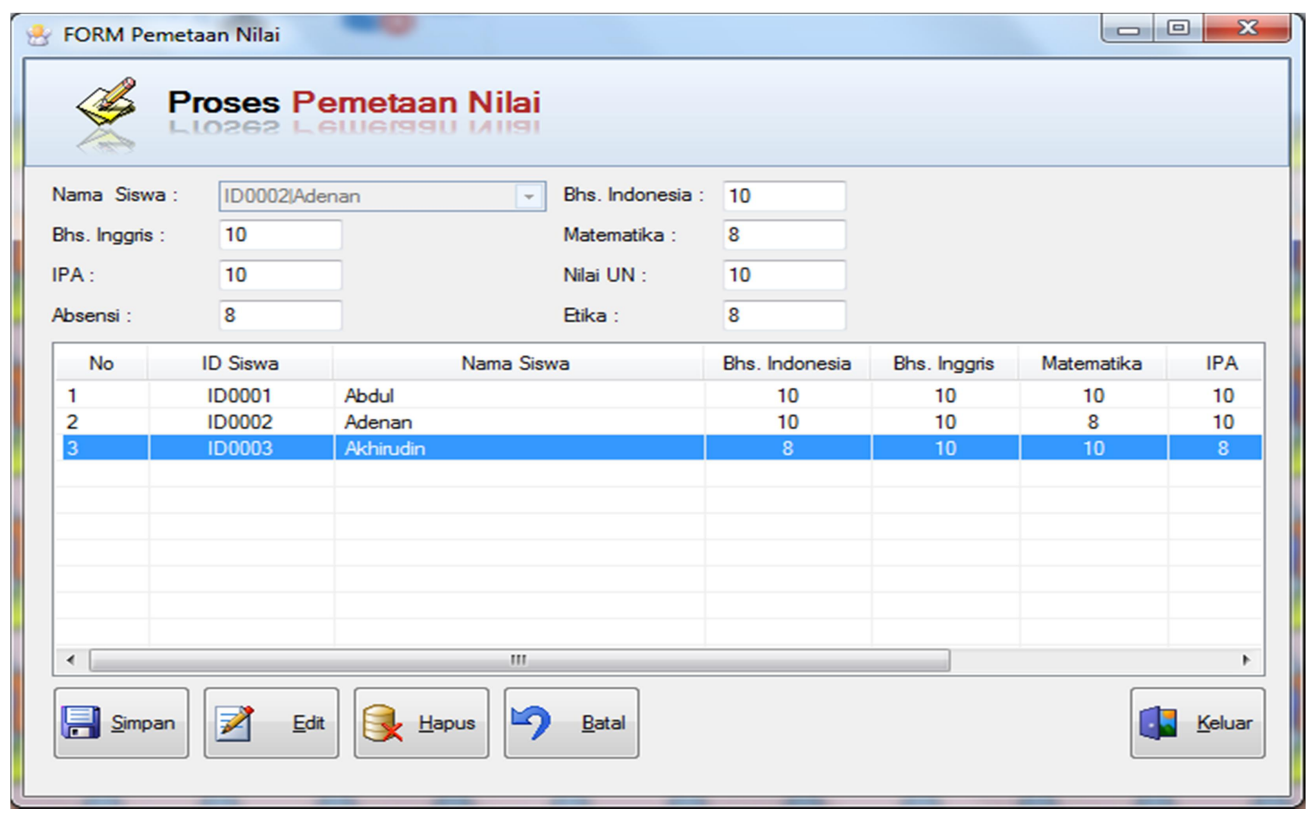

Figure 2. Mapping Value

Figure 2 is an interface that is used to input student value data which will be processed using the PROMETHEE method, and in this data there's will be at least 20 sample value as in table 1 .

*Corresponding Author: Ade Parlaungan Nasution,Email id : Shenbab4u@gmail.com

Article History: Received: Jan 15, 2019, Revised: Feb 10, 2019, Accepted: Mar 04, 2019 


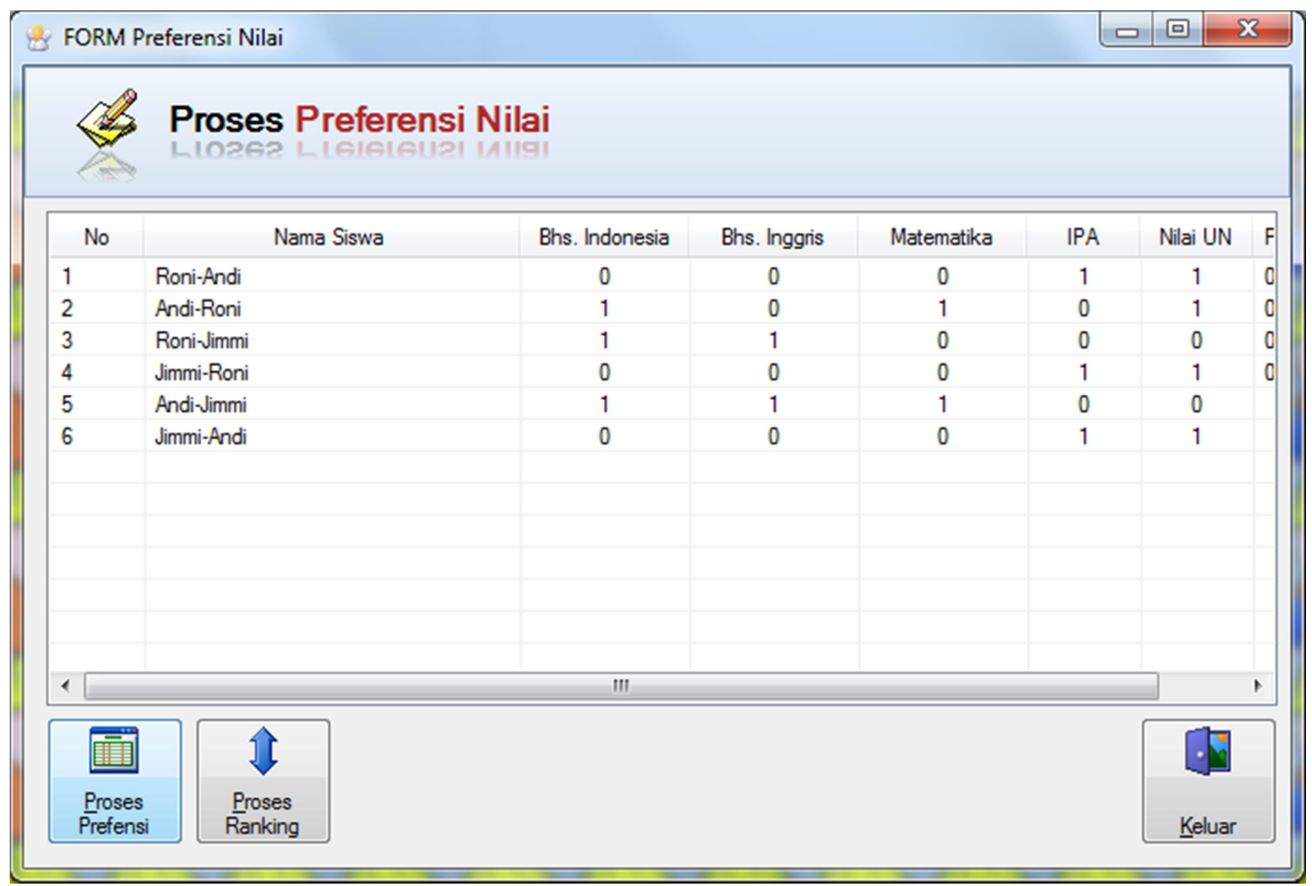

Figure 3. Preference Value

Figure 3 is the result of the preference calculation process by applying the PROMETHEE method and at the end of the process when all data samples are tested it will produce the same value as table 2 .

\section{Conclusion}

The PROMETHEE method that is used as a tool in determining student achievement can help management in making decisions. The PROMETHEE method is not the only method that can be used as a support for decision making and this method can be combined with other methods so that the results are better and more accurate.

\section{References}

[1] M. P. Sari, A. H. Mirza, and Fatmasari, "Decision Support System to Determine The Loan Nominal at KUD Mupakat Jaya Using Decision Tree Method," in The 4th ICIBA 2015, International Conference on Information Technology and Engineering Application, 2015, pp. 250-254.

[2] J.-J. Huang, G.-H. Tzeng, and H.-H. Liu, "A Revised VIKOR Model for Multiple Criteria Decision Making - The Perspective of Regret Theory," in Communications in Computer and Information Science, vol. 35, 2009, pp. 761-768.

[3] D. Nofriansyah, "Application to Determination of Scholarship Worthiness Using Simple Multi Attribute Rating Technique and Merkle Hellman Method," Int. J. Artif. Intell. Res., vol. 1, no. 2, p. 41, Oct. 2017.

[4] D. Siregar, D. Arisandi, A. Usman, D. Irwan, and R. Rahim, "Research of Simple Multi-Attribute Rating Technique for Decision Support," J. Phys. Conf. Ser., vol. 930, no. 1, p. 012015, Dec. 2017.

[5] T. L. Saaty, "Decision making - the Analytic Hierarchy and Network Processes (AHP/ANP)," J. Syst. Sci. Syst. Eng., vol. 13, no. 1, pp. 1-35, Mar. 2004.

[6] M. Kessentini, N. Bellamine, B. Saoud, M. Charrad, and S. Sboui, "MULTI-CRITERIA DECISION SUPPORT SYSTEM COUPLING LOGISTICS AND FINANCIAL PERFORMANCE IN INVENTORY MANAGEMENT."

[7] T. Suryanto, R. Rahim, and A. S. Ahmar, "Employee Recruitment Fraud Prevention with the Implementation of Decision Support System," J. Phys. Conf. Ser., vol. 1028, no. 1, p. 012055, Jun. 2018.

[8] R. F. Jumarni and N. Zamri, "An integration of fuzzy TOPSIS and fuzzy logic for multi-criteria decision making problems," Int. J. Eng. Technol., vol. 7, no. 2, pp. 102-106, 2018.

[9] P. Sona, T. Johnson, C. Vijayalakshmi, and C. Vijayalakshmi, "Design of a multi criteria decision model-fuzzy analytical hierarchy approach," Int. J. Eng. Technol., vol. 7, no. 1.1, pp. 116-120, Dec. 2017.

[10] A. Indahingwati, M. Barid, N. Wajdi, D. E. Susilo, N. Kurniasih, and R. Rahim, "Comparison Analysis of TOPSIS and Fuzzy Logic Methods On Fertilizer Selection,” Int. J. Eng. Technol., vol. 7, no. 2.3, pp. 109-114, 2018. 
[11] M. Behzadian, R. B. Kazemzadeh, A. Albadvi, and M. Aghdasi, "PROMETHEE: A comprehensive literature review on methodologies and applications," Eur. J. Oper. Res., vol. 200, no. 1, pp. 198-215, 2010 .

[12] Fadlina, L. T. Sianturi, A. Karim, Mesran, and A. P. U. Siahaan, "Best Student Selection Using Extended Promethee II Method,” Int. J. Recent Trends Eng. Res., vol. 3, no. 8, pp. 21-29, 2017.

[13] D. Siregar et al., "Multi-Attribute Decision Making with VIKOR Method for Any Purpose Decision," $J$. Phys. Conf. Ser., vol. 1019, p. 012034, Jun. 2018.

[14] M. Mesran, S. D. Nasution, S. Syahputra, A. Karim, and E. Purba, "Implementation of the Extended Promethee II in Upgrade Level of Mechanic,” Int. J. Sci. Res. Sci. Technol., vol. 4, no. 2, pp. 125-130, 2018. 